\title{
Recursos e estratégias de pesquisa online e offline: um estudo no primeiro ciclo do ensino básico
}

\author{
Lurdes Carvalho; Atina Ramos; Joana Baptista \\ Instituto de Educação- Universidade do Minho
}

\begin{abstract}
Resumo
As crianças evidenciam uma atitude de curiosidade e de questionamento, procurando encontrar respostas para as suas dúvidas. Nesta atitude reside já a sua predisposição para a pesquisa. Torna-se, por isso, importante que os professores estimulem e integrem a pesquisa no processo educativo. Este artigo relata o percurso investigativo no contexto da intervenção pedagógica concretizado numa turma do $4 .^{\circ}$ ano de escolaridade do $1 .^{\circ}$ ciclo do ensino básico. As crianças foram confrontadas com a complexidade do processo de pesquisa trabalhando com diferentes meios, nomeadamente internet, livros e entrevista. Metodologicamente tratou-se de um estudo de caso de caráter descrito-interpretativo.
\end{abstract}

Palavras-chave: recursos de pesquisa online e offline; estratégias de pesquisa; ensino básico

\section{Introdução}

Este artigo baseia-se na descrição e análise de uma investigação pedagógica desenvolvida durante quatro meses numa escola de $1 .^{\circ}$ Ciclo do Ensino Básico, situada na cidade de Braga. Participaram vinte e seis crianças, do $4^{\circ}$ ano de escolaridade, com idades compreendidas entre os nove e os dez anos.

A escola situa-se na área de influência de bairros sociais com presença de uma população flutuante de imigrantes e cuja língua materna não é o Português. Uma parte significativa dos alunos é oriunda de famílias que vivem nos bairros sociais que, do ponto de vista socioeconómico, se situam num estrato de baixos recursos e com fraco acesso a bens culturais. Algumas destas famílias revelam graves debilidades ao nível da sua estruturação, com problemas que vão desde o desemprego, à toxicodependência, ao alcoolismo, baixa escolarização e outros. Simultaneamente, são recorrentes as referências relativas à baixa escolarização dos agregados familiares, associadas ao desemprego ou a situações de precariedade social e económica. Este agrupamento de escolas foi incluído na definição de Território Educativo de Intervenção Prioritária 2 (TEIP2) e tem como principais objetivos o combate à violência e ao precoce abandono escolar, bem como promover o acompanhamento educativo adequado para que, as crianças atravessem, com um determinado grau de qualidade, da vida na escola para a vida ativa.

Foi intenção principal deste estudo a promoção da competência de aprender a aprender, a partir do desenvolvimento de aprendizagens sobre os processos de pesquisa numa interação constante entre prática e teoria. Concretamente, pretendemos desenvolver nos alunos competências de pesquisa para a construção de novos conhecimentos. Procuramos ainda perceber o papel do professor para que os alunos atinjam a emancipação social fundamental para a vida em sociedade, cada vez mais rodeada de novas tecnologias de informação.

\section{Pesquisa como princípio educativo: desenvolvimento de competências}

As crianças desde muito cedo evidenciam uma atitude de curiosidade em encontrar respostas para as suas dúvidas, aspeto considerado por Demo (1992) como a existência de uma atitude de pesquisa. Tendo em conta esta atitude das crianças, torna-se importante estimulá-la e integrá-la no processo educativo. A emancipação deste processo no meio escolar terá como ponto de partida uma postura de questionamento criativo, que levantará desafios para os quais os alunos inventem soluções, descubram e criem relações alternativas, atitudes motivadoras para o começo da sua própria emancipação social. Segundo Demo (2003, p.10) pelo termo questionamento "compreende-se a referência à formação do sujeito competente, no sentido de ser capaz de, tomando consciência crítica, formular e executar projeto próprio de vida no contexto histórico. Não significa apenas criticar, mas, com base na crítica, intervir alternativamente".

O trabalho pela pesquisa amplia a curiosidade, a inquietude, o desejo de descoberta e criação e, sobretudo, uma atitude emancipatória da construção do sujeito social competente e organizado (Demo, 1992). Para tal, a educação pela pesquisa deverá tornar-se um processo regular usado pelos professores, tendo sempre como ponto de partida o questionamento que, ao longo do tempo, se tornará reconstrutivo. Este será, então, o processo que permitirá ao aluno reconstruir os seus conhecimentos por meio da interpretação própria, da formulação pessoal, o que permitirá desenvolver o saber pensar e o aprender a aprender. Tendo em conta o questionamento como processo fundamental para a reconstrução do conhecimento, o professor competente deverá aproveitar todos os momentos de motivação lúdica para o impulsionar ainda mais, concebendo-o assim como um processo mais produtivo, provocador, investigador e motivador.

Neste sentido, o saber procurar e questionar (pesquisa) é a mola propulsora do "questionamento reconstrutivo"; portanto o desafio da elaboração própria surge quando o 
aluno é motivado a tomar a iniciativa, apreciar a leitura e biblioteca, buscar dados e encontrar fontes, manejar conhecimento disponível e até mesmo o senso comum (Demo, 2003, p.28).

Cabe assim à escola disponibilizar diversos materiais e, ao mesmo tempo, trabalhar de forma a criar propostas por meio das quais os alunos aprendam a gerir, a selecionar e a tratar as informações e os conhecimentos de forma competente e com significado próprio. Uma vez que a pesquisa "é atividade inerente ao ser humano, um modo de aprender o mundo" (Veiga, 2004, citado por Freiberger \& Berbel, 2010, p.228), a educação através da pesquisa deverá afirmar-se, pois passa por estimular a criatividade, a atitude investigativa e a curiosidade.

Considerando a pesquisa como um instrumento de aprendizagem, então aprender a pesquisar deverá, fazer parte do dia-a-dia da escola e da sala de aula, visto que "é muito difícil imaginar ação educativa que não seja precedida por algum tipo de investigação” (Veiga, 2004, p.17). O papel do professor passa, então, essencialmente por proporcionar aos alunos experiências em que possam desenvolver capacidades ao nível dos três passos importantes da pesquisa, particularmente i) na procura de material, ii) na interpretação própria e iii) na reconstrução do conhecimento (Demo, 2003).

O primeiro passo, nomeadamente a procura de material dá início à investigação e, consequentemente, ao desenvolvimento de uma atitude investigativa. Esta etapa tem como principal foco fomentar no aluno a iniciativa no que diz respeito à procura de informações, nos diferentes tipos de fontes às quais tem acesso. A concretização deste procedimento implica que a escola/sala de aula esteja equipada com algumas fontes de informação para que os alunos possam usufruir desse material livremente. Caso estes recursos sejam escassos, cabe ao professor, através de diversos tipos de oportunidades, motivar a procura de materiais que ele mesmo cria e/ou disponibiliza. Então, isto significa que “o professor criativo induz o aluno a criar também, ao montar materiais que permitam ao aluno manipular, experimentar, ver de perto, e principalmente refazer" (Demo, 2003, p. 22).

No momento seguinte, assenta a motivação para o desenvolvimento das interpretações próprias, momento em que o aluno dá início à elaboração própria. Nesta fase é importante mostrar a diferença que aparece nos alunos, por um lado quando copiam e decoram textos e, por outro, quando os interpretam, autonomamente, para os fazer ou refazer. Tudo o que possui uma marca pessoal passa a tornar-se significativo, aspeto que, por sua vez, torna necessário o progresso na capacidade de formulação e elaboração próprias. E ainda, “aparecendo a elaboração própria, torna-se visível o saber pensar e aprender a aprender” (Demo, 2003, p. 24). De modo geral, pode-se assim dizer que "aprende-se significativamente a partir daquilo que já se aprendeu de modo significativo e o que já se aprendeu, ou construiu, inclui esquemas, constructos, representações mentais, etc.” (Valadares \& Moreira, 2009, p. 121).

O estádio seguinte passa pela procura da reconstrução do conhecimento que implica um processo complexo e sempre recorrente, que começa naturalmente pelo uso do senso comum. Conhecemos a partir do conhecido. Esta representa a dinâmica central da competência, à medida que o simples fazer é superado pelo saber fazer e pelo constante refazer (Demo, 2003, p.25).

Por isso, cabe ao professor conhecer os interesses e motivações do contexto de modo a aproveitar aquilo que o aluno já sabe para que, os seus conhecimentos prévios, a partir da interpretação de novas informações, este tenha oportunidade de reconstruir o seu conhecimento. Isto porque toda a atividade de construção de conhecimento se baseia na integração de símbolos conhecidos. Tal como Coll e seus colaboradores (2001, p. 89) referem "se pretendemos que o aluno adquira as capacidades necessárias para atuar deste modo devemos ajudá-lo a dominar os diferentes sistemas e códigos culturais”. O aluno irá atribuir aos conhecimentos (re) construídos um sentido próprio o que, por sua vez, tornará a aprendizagem mais significativa.

Tendo em conta estas ideias acerca do processo de pesquisa, e uma vez que em cada uma das fases se pode tornar necessário voltar atrás, tanto para uma nova procura de materiais ou informações como para uma nova análise e exploração da mesma, torna-se possível uma reorganização deste processo através de um procedimento cíclico que integra diferentes passos, de forma a estimular nas crianças o espírito de curiosidade e investigativo. Neste sentido, poderá sequencializar-se em quatro passos distintos (Procurar; Analisar/Explorar; Selecionar/Organizar; Elaborar/Reconstruir), existindo a possibilidade de, sempre que necessário, recuar novamente a um dos passos anteriores. Cabe assim ao professor estabelecer metas para cada um destes passos e delinear atividades/propostas que deem resposta aos objetivos previamente pensados. Pensando e estimulando o processo de pesquisa deste modo, torna-se possível o desenvolvimento das competências de pesquisa e do saber por parte das crianças.

\section{Método}

O presente projeto assumiu a metodologia de investigação-ação porque se constitui uma forma uma forma de questionamento reflexivo e coletivo de situações sociais, realizado pelos participantes, com vista a melhorar a racionalidade e o ajustamento das próprias práticas educacionais bem como a compreensão dessas práticas e as situações nas quais são desenvolvidas (Matos, 2004, citado por Fernandes, s/d., p.3). O recurso a esta metodologia de trabalho para estudar o desenvolvimento das competências de pesquisa, permite entender e investigar, a partir de um processo cíclico e reflexivo, os métodos utilizados e os seus efeitos, com o objetivo de melhorar a prática pedagógica.

\section{Questão de investigação e objetivos}

O facto de vivermos numa era tecnológica, onde as informações são processadas rapidamente por meio de diferentes meios, não exclui quer o recurso a outros meios de pesquisas quer a delineação das estratégias mais adequadas para o fazer. Através de uma diversidade de estratégias motivadoras pretendeu-se que as crianças desenvolvessem as competências essenciais para se 
tornarem cidadãos com curiosidade para aprender mais através de pesquisas e com recursos diversificados.

Partindo da questão central de investigação "quais os contributos do desenvolvimento das competências de pesquisa na construção da aprendizagem?’ pretendeu-se atingir os seguintes objetivos: i) Perceber de que forma o trabalho por meio da pesquisa influencia a aprendizagem das crianças; ii) Averiguar o trajeto evolutivo dos alunos relativamente aos conhecimentos sobre o processo de pesquisa.

As técnicas e os instrumentos de recolha de dados utilizados foram: observação participante, constante e pormenorizada; notas de campo; produções das crianças; entrevistas às crianças; e diálogos com a professora titular.

\section{Estratégias de Intervenção}

As estratégias de intervenção utilizadas tiveram sempre como objetivo possibilitar aos alunos uma abordagem curricular integrada e harmoniosa, repleta de experiências significativas e reais, permitindo o seu pleno desenvolvimento. Deste modo, o Projeto Curricular Integrado (Alonso, 2001), permitiu aos alunos "não só desenvolverem competências de pesquisa e de organização da informação, mas também de estabelecerem relações entre os conhecimentos, por forma a adquirirem ainda competências de vivência numa sociedade que se rege por princípios de uma democracia participativa” (Cortesão \& Leite, 2002, p.35).

Foram propostas diversas estratégias, tais como: momentos de procura de informação acerca de vários assuntos, organização de trabalhos de grupo para a seleção e o tratamento dos dados previamente recolhidos. Simultaneamente, foram propostas atividades em grande grupo para a sintetização/sistematização da informação, como forma de registar os conhecimentos construídos através do recurso a diferentes estratégias de registo; a organização de momentos de apresentação do trabalho de pesquisa realizados, que funcionaram como momentos de partilha e de valorização dos conhecimentos previamente construídos. Estes momentos permitiram ainda perceber os conhecimentos construídos pela criança ao longo de todo o processo.

Para que fosse visível uma resposta à questão central de investigação, tornou-se essencial a realização de uma constante avaliação das estratégias que os alunos, ao longo do tempo, iam selecionando para os seus trabalhos de pesquisa. Para além de uma contínua reflexão que permitiu perceber se os objetivos estipulados foram ou não alcançados, tivemos ainda em conta a análise dos trabalhos das crianças, das suas interações bem como dos pequenos diálogos

Ao longo de todo este projeto existiu um processo contínuo e sistemático de investigação, planificação, ação e reflexão, com o intuito a avaliar e repensar, ciclicamente nas formas mais eficazes de tornar as propostas mais relevantes e significativas para os alunos. Todo este processo se concretizou de modo participativo e colaborativo em espaço de sala.

\section{Desenvolvimento da intervenção}

A avaliação dos conhecimentos das crianças relativamente ao trabalho por meio da pesquisa foi construída desde as semanas de observação, uma vez que tivemos a oportunidade de observar e analisar a apresentação oral de um trabalho de pesquisa, concretizado em pequenos grupos, relativo à vida e obra de José Saramago. A observação deste momento levou-nos a refletir acerca dos conhecimentos das crianças relativamente aos vários passos do processo de pesquisa, o que permitiu recolher vários dados que se demostraram essenciais para o desenrolar do projeto. Com efeito, durante a apresentação desses trabalhos de grupos, algumas crianças demonstravam insegurança em determinadas partes do seu trabalho, sugerindo o não seguimento de algumas etapas essenciais da mesma (a análise e seleção da informação recolhida) e dificultando assim a construção dos novos conhecimentos.

Verificou-se uma grande tendência para fazer as pesquisas apenas através da Internet e descobrimos que os alunos apenas se baseavam em copiar e colar a informação, não recorrendo a qualquer tipo de seleção, análise e sistematização da mesma, o que parece demonstrar não ter existido uma elaboração/construção própria do pensamento de cada criança. Pudemos constatar que os alunos não analisaram ou exploram, nem selecionaram as informações que consideravam pertinentes para conseguirem chegar à elaboração própria e consequentemente à reconstrução dos próprios conhecimentos. As crianças não sabiam que para o desenvolvimento de um trabalho de pesquisa era necessário analisar e explorar a informação, selecioná-la e organizá-la para posteriormente elaborar o seu próprio texto.

Com o intuito de recolher ainda mais informações que nos pudessem clarificar quanto ao nível de desenvolvimento das crianças relativamente às suas competências de pesquisa, foi implementado um momento para observar especificamente aspetos referentes aos vários passos que integram o processo de pesquisa. No momento de iniciar o trabalho de pesquisa, apercebemo-nos que grande parte da turma não sabia como analisar e selecionar a informação mais relevante para a temática em questão, pois sempre que eram questionadas acerca de como fazer, surgiram respostas como "Vamos copiar o que está aqui!". Embora dentro dos grupos tenham conseguido encontrar estratégias para o fazer, tornou-se imprescindível refletir sobre a importância da análise, exploração, seleção e organização da informação recolhida para a construção de novos conhecimentos através de trabalhos de pesquisa.

\section{Primeiro momento de pesquisa}

Antes iniciar o momento de pesquisa foi apresentado em grande grupo, um conjunto de curiosidades que as crianças pretendiam descobrir sobre o tema em questão. 
Como a atividade de pesquisa foi feita através da internet e pelo facto de o mundo virtual ser muito vasto, tornou-se necessário que, previamente se estabelecessem objetivos para focalizar a intenção das pesquisas das crianças. Este momento, para além de ajudar a orientar as suas pesquisas, foi também fundamental para que na ocasião da procura da informação os alunos não se dispersassem nem vagueassem, centrando-se apenas na mais relevante.

De seguida, quando deram início à pesquisa, apesar de ter sido notória a motivação gerada pelo recurso às tecnologias de informação e comunicação, apercebemo-nos que as crianças estavam a sentir grandes dificuldades na utilização do motor de busca. Com efeito, colocavam frases completas em vez de palavras-chave o que automaticamente dificultava a pesquisa que queriam realizar. Esta situação ajudou ainda a perceber a falta de experiência e de competências que as crianças possuem no que diz respeito ao desenvolvimento de trabalhos de pesquisa, pelo que uma breve explicação acerca do modo como devem fazer a pesquisa através de palavras-chave.

Após este pequeno diálogo as crianças, em pequeno grupo, procuraram as informações, e sempre que pensavam ter encontrado a resposta a cada uma das curiosidades previamente estabelecidas, discutiam, analisavam e exploravam com o grupo, para posteriormente registarem essas informações no caderno diário.

Depois de encontrada e analisada a informação que consideravam necessária para dar resposta à questão em causa, e como forma de promover a capacidade de seleção e organização dos dados previamente recolhidos, decidimos (em grande grupo) elaborar trabalho em pequenos grupos com esses mesmos registos, um cartaz-síntese de todo o trabalho. Cada um dos pequenos grupos organizou o cartaz conforme a sua preferência, quer por esquemas quer por pergunta-resposta. Por fim, houve um momento de partilha em que cada grupo mostrou e explicou o seu cartaz aos restantes colegas da turma, uma vez que as informações de cada grupo se complementavam.

Esta atividade mostrou aos alunos a importância dos vários passos subjacentes ao processo de pesquisa, permitindo também despertar nos mesmos o gosto por este tipo de trabalho. O facto de as crianças terem conseguido dar resposta às curiosidades previamente estabelecidas, mostra a importância da promoção deste tipo de experiências de aprendizagem para que as tenham a oportunidade de desenvolver as competências de pesquisa essenciais para a construção ativa dos próprios conhecimentos.

Para o professor, este momento foi uma importante situação de avaliação dos conhecimentos e dificuldades dos alunos para que pudesse conhecer as suas evoluções e, a partir daí atuar no sentido de os desafiar cada vez mais.

\section{Segundo momento de pesquisa}

Depois de um pequeno debate sobre as informações recolhidas numa palestra dada pela mãe de um aluno, tornou-se necessário uma nova busca de informações, como forma de recordar alguns aspetos mencionados ao longo da palestra. A partir dessa exploração, tornou-se mais fácil o registo em grande grupo das informações relevantes. As crianças por meio do debate e chegando a acordo decidiram quais as informações que iriam selecionar e qual a sequencialização que iram atribuir. Assim, esta tarefa para além de ter permitido a vivência de mais uma experiência ao nível da consciencialização das competências de pesquisa, também proporcionou aos alunos o desenvolvimento de atitudes ao nível do trabalho cooperativo, do respeito pela opinião do outro, ou seja possibilitou o desenvolvimento das competências sociais essenciais para a vida em comunidade.

Uma vez que uma das informações que as crianças retiraram da pesquisa incidia em algumas personalidades marcantes da época, solicitaram a construção de um fantoche relativo às mesmas. A seguir realizaram pequenos diálogos dramatizados com os mesmos. Num momento final, como forma de criar um momento de partilha das informações foi criado um momento de apresentação dramatizada dos pequenos diálogos que tinham construído.

A apresentação destes pequenos diálogos dramatizados por meio de fantoches, possibilitou perceber que, depois dos vários passos que realizaram, os alunos possuíam as suas ideias bem organizadas sobre a temática em questão, o que demonstra que adquiriram novas aprendizagens. Verificou-se que a aprendizagem por meio da pesquisa, pode constituir-se como uma estratégia de combate à receita pronta. Deste modo o professor deverá realizar um questionamento constante, para que possa apoiar o aluno na construção do próprio conhecimento.

\section{Terceiro momento de pesquisa}

Nesse momento interessou-nos perceber as ideias já construídas pelo grupo acerca dos vários passos essências deste tipo de trabalho. Através de um pequeno diálogo tornou-se possível verificar um grande avanço no processo de pesquisa. Com efeito, o grupo já se tinha apercebido da necessidade de, antes de dar início à procura de informações, delinear pequenas sub questões sendo esse um grande apoio no momento da busca de novos dados.

\section{Resultados}

A partir das observações durante as atividades, das entrevistas, dos trabalhos dos alunos e das respostas escritas a algumas questões, foi possível obter resultados importantes sobre o processo evolutivo das crianças relativamente ao processo de pesquisa.

De um modo geral, todas mostraram ter construído a noção de que para adquirirmos novas informações acerca de determinado assunto, se torna necessário inicialmente fazer uma primeira recolha de dados através de um conjunto de atividade integradoras que estimulem as crianças para "a observação, a curiosidade, a pesquisa e a atitude científica perante a realidade” (Alonso, 2001, p.16). Para isso, a internet foi o meio de pesquisa mais 
referenciada, aspeto que poderá ser explicado devido ao facto de vivermos numa sociedade cada vez mais eletrónica, onde as crianças cada vez mais cedo contactam com as novas tecnologia e onde a informação se pode encontrar com maior facilidade.

Foi ainda evidente a consciência de grande parte do grupo para a necessidade de, durante o trabalho de pesquisa, existir um momento de análise e exploração dos dados recolhidos. As crianças fizeram comentários como, "Ele tem que fazer como nós, pesquisa na internet, depois ver o que é mais importante e depois escrever"(A8). Afirma uma aluna: "Primeiro ia à internet. Depois passava a informação para o meu trabalho. Mas primeiro lia e via as coisas mais importantes." (A9);"Pesquisar; Analisar; e escrever o mais importante." (A10). Esta resposta foi dada numa fase adiantada do trabalho com as crianças o que revela a consciencialização das crianças acerca do processo de pesquisa, implicando também o desenvolvimento das competências implícitas no mesmo.

Respostas do tipo "Organizava as ideias e fazia o trabalho" (A4) e "Quase no fim juntava-as e ordenava-as. Por fim fazia um texto" (A1) permite-nos afirmar que os alunos sabem que para terminar uma pesquisa se torna necessário registar aquilo que descobriram por palavras próprias, já que antes destas atividades eles se limitavam a copiar as informações que recolhiam. Este é um meio de combate à receita pronta, o que "significa habituar o aluno a ter iniciativa, em termos de procurar livros, textos, fontes, dados, informações. Visa-se superar a regra comum de receber as coisas prontas, sobretudo apenas reproduzir materiais existentes" (Demo, 2003, p.21).

Contudo, é também de referir que houve algumas crianças que não conseguiram chegar a estas noções, uma vez que afirmavam que o processo de pesquisa implicava a procura de materiais, a leitura e a cópia das informações. Afirmar que "Pesquisar na internet depois ler e copiar o que é mais importante" (A11) revela a necessidade de continuar este tipo de trabalho com as crianças, não basta uma ou outra iniciativa pontual. Só assim terão oportunidade para construírem novos conhecimentos e terem um papel ativo no processo de construção das aprendizagens o que, por sua vez, ajudará a que sejam cidadãos com atitude e espírito investigativo. Este é um aspeto que se torna essencial quer para o total desenvolvimento e emancipação do aluno enquanto ser humano, quer para a vida na sociedade atual.

\section{Referências Bibliográficas}

Alonso, L. (2001). A abordagem de Projeto Curricular Integrado como uma proposta de inocação das práticas nas Escola Básica. Baga.

Coll, C., Martín, E., Mauri, T., Miras, M., Onrubia, J., Solé, I., \& Zabala, A. (2001). O construtivismo na sala de aula. Novas perspectivas para a aç̧ão pedagógica. Lisboa: Edições Asa.
Cortesão, L., Leite, C., \& Pacheco, J. A. (2002). Trabalhar por Projetos em Educação. Porto: Porto Editora.

Demo, P. (1992). Pesquisa: princípio científico e educativo. São Paulo: Cortez.

Demo, P. (2003). Educar pela pesquisa. Campinas: Autores Associados.

Fernandes, A. M. (s.d.). A investigação-acção como metodologia.

Freiberger, R., \& Berbel, N. (2010). A importância da pesquisa como princípio educativo na atuação pedagógica de professores de educação infantil e ensino fundamental. In Cadernos de Educação (pp. 207-245).

Valadares, J. A., \& Moreira, M. A. (2009). A Teoria da Aprendizagem Significativa. Coimbra: Almedina.

Veiga, I. (2004). As dimensões do processo didático na ação docente. In Encontro Nacional de Didática e Prática de Ensino (pp. 13-30). Curitiba: Champagnat 